\title{
Shadow Values and the Politics of Extrapolation Brian Balmer
}

If the metaphor of the "shadow" is to have analytical bite, then it must amount to more than just a substitution for more direct terms such as missing, absent and neglected. As the papers in this special edition demonstrate, a shadow is cast by something and signifies something about whatever cast the shadow - it is not simply a gap. ${ }^{1}$ Moreover, the term shadow data reminds us that open science and secret science are not polarized opposites, rarely is everything totally hidden or entirely closed. As geographer, Trevor Paglen notes, even a blank spot on the map signals that something there is of interest to someone (Paglen 2009). While this point is made by all of the contributors here, it leads to a further observation. Frequently, openness and secrecy are written about from the perspective of those on the outside. The notion of shadow data reminds us that what is closed to many may nonetheless be open to a select few: people inhabit different worlds with respect to the same information. In this respect, shadow data might be totally submerged and unavailable, but alternatively, as with a camouflaged site or an open day at a military establishment, it might hide its secrets by placing them in plain sight (Forsyth, 2014; Balmer 2015).

It is also reassuring that the contributors to this special edition keep in sight those who create, maintain, curate or otherwise have some relationship with data. This is because the status of the data as open or closed, present or absent, is not merely a statement about data but constitutes the identity of these creators, users and curators. So, for example, when data or other information is given an official classification (Top Secret, Secret, Unclassified etc.) someone needs to be vetted to access that data - a particular type of person for each level of classification is imagined and created through the vetting process (Balmer 2012, pp57-71). It is equally apparent in relation to the "citizen scientists," successful archaeologists, and "open scientists" discussed in this collection. A related consequence of classifying data as open or closed, in the light or in shadow, is that data becomes valorized. This value varies depending on group interests, but value also rests on its place in the taxonomic scheme as much as on any inherent property of the data. This can vary historically and spatially. So, in Elena Aronova's paper she discusses the Glavit lists, where even the word "earthquake" could cause a paper to be classified; thus she draws an implicit comparison with the different value attached to that word in Western journals or outside of the Cold War. Equally, at a recent conference on science and security, Brian Rappert's discussion of Wikileaks drew attention to the dynamics of attaching value to leaked information, which is subsequently devalued as it is shown to be not the whole story (Rappert 2016). A corollary manifestation of devaluing in the Wikileaks story was widely reported diplomatic cables that turned out to be little more than a trade in trivial insults.

The notion of shadow data also invokes a moral economy. The trivial fact that data can be separated into ostensibly open and closed data shifts our analytical attention to the ethics of collection, use and storage. In short, what are the justifications and

\footnotetext{
${ }^{1}$ My commentary draws also on my 20 or so years of research on the history of biological and chemical warfare - a topic that relies for its data on classified, declassified, redacted and 'shadow' documents.
} 
consequences of making data open or closed? Here, Nadine Levin and Sabina Leonelli go quite some distance in considering how notions of credit change within the scientific reward system, as not only does some data disappear but so may some contributors who create or curate the data. It is important to add that this disappearance might be split along lines of seniority, gender or as visible scientists versus invisible technicians (Shapin 1989). A different moral economy is suggested in Linsey McGoey's treatment of neglect: data on wealth inequality has not been gathered because of a historical legacy in which an entire problematic has been written out of the academic economic canon. Other ethical questions entail pinning down the specificities of particular types of data, rather than talking about openness and shadow data in general terms. So, with respect to sites, a military database of potential targets may differ in morally significant ways from a biomedical collection. Likewise the type of data collected might raise particular ethical problems with respect to openness and shadow data, for example future research under this rubric might explore the issues that might be raised around collecting the intimate data of civilian deaths in war or of child abuse cases. All this points to a need to continually map the moral landscape of open science and shadow data.

Finally, the idea of shadow data also prompts us to revisit the idea of extrapolation. Data that are open and available have to be made to speak for data that is unavailable. This is nowhere more apparent than in Alison Wylie's discussion of the work involved in making use of legacy data. Extrapolation has its own politics and Science and Technology Studies has long recognized this in its analysis of regulatory science. For example, regulator's extrapolation of carcinogenicity to humans from the number of liver tumours in mice exposed to a pesticide, has been contested by different groups with different institutional goals (Gillespie et al 1979). Extrapolation also occurs when data are used to simulate a situation whether through a model, a reenactment or a so-called "serious game." Studies of the use of such techniques during the Cold War, to simulate a nuclear attack, gave rise to the question of which parts of the simulation mattered (Ghamari-Tabrizi 2000). While there could be complete agreement on some aspects of the simulation, the very nature of role-playing an unknown nuclear attack meant that some elements of the design had to be presumed significant or insignificant to the outcome. In a world increasingly basing security on this form of preparedness (Cooper 2006, Lakoff 2007), the politics of extrapolation and the politics of shadow data could become a timely way to make sense of these changes.

So, shadows are not mere absences and gaps. They are signposts; they reveal and conceal. And they are attended by their own peculiar value systems, moral economies, and a politics of extrapolation that make them fertile ground for scholars in Science and Technology Studies.

\section{References:}

Balmer, B (2015), 'An Open Day for Secrets: Biological Warfare, Steganography and Hiding Things in Plain Sight' in B. Rappert and B. Balmer (eds), Absence in Science, Security and Policy: From Research Agendas to Global Strategies (Basingstoke: Palgrave). 
Balmer, B (2012), Secrecy and Science: A Historical Sociology of Biological and Chemical Warfare (Farnham: Ashgate).

Cooper, M. (2006) 'Pre-empting emergence: The biological turn in the war on terror', Theory, Culture \& Society, 23(4), pp. 113-135.

Forsyth, I. 2014. 'Designs on the desert: camouflage, deception and the militarization of space' Cultural Geographies 21(2): 247-65

Ghamari-Tabrizi, S (2000), 'Simulating the Unthinkable: Gaming Future War in the 1950s and 1960s', Social Studies of Science, vol. 30, 2: pp. 163-223.

Gillespie, B. Eva, D and Johnston, R (1979), 'Carcinogenic Risk Assessment in the United States and Great Britain: The Case of Aldrin/Dieldrin', Social Studies of Science August 1979 vol. 9 no. 3 265-301.

Lakoff, A. (2007) 'Preparing for the next emergency', Public Culture, 19(2), pp. 247271.

Paglen, T (2009), Blank Spots on the Map: The Dark Geography of the Pentagon's Secret World. New York: Dutton.

Rappert, B (2016), 'Absence and the Displaying of Secreted Histories', keynote speech at conference on Science/Technology/Security: Challenges to Global Governance?, UCL Global Governance Institute, London, July 20-21 2016.

Shapin, S. (1989). 'The invisible technician'. American Scientist, Vol. 77, No. 6 (November-December 1989), pp. 554-563. 